\title{
Transmissible Substrate-utilizing Ability in Enterobacteria
}

\author{
By H. WILLIAMS SMITH AND ZOË PARSELL \\ Houghton Poultry Research Station, Houghton, Huntingdon PEI $72 D A$
}

(Received 29 July 1974; revised 3 October 1974)

\begin{abstract}
SUMMARY
Three of I 52 strains of Escherichia coli transmitted their ability to utilize sucrose $\left(\mathrm{Sac}^{+}\right)$to other strains by conjugation. The transfer factor of one of them and of a $\mathrm{Sac}^{+}$Salmonella thompson strain was thermosensitive. The raffinose-utilizing ability of 27 of $163 \mathrm{E}$. coli strains was also transmissible. Transmissible raffinoseutilizing ability was a feature of porcine enteropathogenic strains possessing the K88 antigen. The determinants controlling raffinose utilization (Raf) and K88 antigen production were commonly transmitted together from these strains; so also was the determinant controlling enterotoxin production, but to a lesser extent. It was not possible to transfer lactose-utilizing ability from 320 strains of $E$. coli, salicinutilizing ability from $\mathrm{I} 2$ strains of $E$. coli or dulcitol-utilizing ability from 99 strains of $E$. coli and 88 strains of salmonellae.

Sucrose- and raffinose-utilizing ability were transmitted separately to several Salmonella sp., including Salm. typhi, to Shigella flexneri and Sh. sonnei and to a variety of strains of $E$. coli.

A strain of Salm. typhimurium in which Sac had been established and a strain of $E$. coli in which Raf had been established survived less well in the alimentary tract of chickens than their $\mathrm{Sac}^{-}$or Raf- parent strains.
\end{abstract}

\section{INTRODUCTION}

Because we found that the sucrose-utilizing ability of four epidemiologically-related strains of Salmonella thompson received from Professor S. S. Kasitiya of the University of Quebec was controlled by a transmissible plasmid (unpublished observation) we decided to determine the incidence in enterobacteria, and especially in Escherichia coli, of strains whose ability to utilize substrates sometimes used in their identification was plasmid-controlled. Experiments were also conducted to establish whether plasmid-determined substrateutilizing ability conferred survival value on organisms inhabiting the alimentary tract.

When this work was nearing completion, Ørskov \& Ørskov (I973) reported that six of eleven strains of $E$. coli that transmitted ability to produce hydrogen sulphide also transmitted ability to ferment raffinose, and Le Minor et al. (I973) reported that of eleven Salmonella strains that fermented sucrose, three, Salm. agona, Salm. ohio and Salm. bovis morbificans, transmitted this property.

\section{METHODS}

Bacterial strains. The epidemiologically-unrelated strains examined for transmissible substrate-utilizing ability were maintained on Dorset egg medium at $5{ }^{\circ} \mathrm{C}$. Five strains were used as prospective recipients. These were: (i) Escherichia coli KI 2 Proto, a lac ${ }^{+}$prototrophic strain that could not utilize sucrose, salicin or raffinose, either resistant to nalidixic acid $\left(n a l^{r}\right)$ and spectinomycin $\left(s p c^{r}\right)$ or to nalidixic acid and ampicillin $\left(a m p^{\mathrm{r}}\right)$. (ii) Escherichia coli KI 2 Auxo, a $n a l^{\mathrm{r}} s p c^{\mathrm{r}} l a c^{-}$strain that required proline, histidine and tryptophan and could 
not utilize dulcitol, salicin, sucrose or raffinose. (iii) Escherichia coli D282, a nalr prototrophic $\mathrm{O} 8: \mathrm{K}^{-}: \mathrm{H}^{-}$strain that did not possess a transfer factor $\left(\mathrm{Tra}^{-}\right)$, could not utilize raffinose, sucrose, dulcitol or salicin and was a good recipient of the plasmid controlling production of the K88 antigen (Ørskov \& Ørskov, 1966). (iv) Escherichia coli Pro4, a nalr $\mathrm{Tra}^{-}$prototrophic Or39:K82 strain that could not utilize raffinose, sucrose, dulcitol or salicin. (v) Salmonella typhimurium 576, a nalr $\mathrm{Tra}^{-}$strain of phage type 36 .

Synthetic medium. This contained $(\mathrm{g} / \mathrm{l}): \mathrm{K}_{2} \mathrm{HPO}_{4}, 7 ; \mathrm{KH}_{2} \mathrm{PO}_{4}, 3 ;\left(\mathrm{NH}_{4}\right)_{2} \mathrm{SO}_{4}, \mathrm{I}$; $\mathrm{MgSO}_{4} \cdot 7 \mathrm{H}_{2} \mathrm{O}, 0 \cdot \mathrm{I} ; \mathrm{NaCl}, 5$; agar I 5. Lactose, sucrose, raffinose, dulcitol or salicin ( $5 \mathrm{~g} / \mathrm{l}$ ) and, when required, growth factors $(25 \mathrm{mg} / \mathrm{l})$ and antibiotics $(20 \mathrm{mg} / \mathrm{l})$ were added immediately before the medium was poured into Petri plates.

Substrate-utilizing tests. Broth cultures were streaked on to plates of synthetic medium containing the substrate under test and the plates incubated at $37{ }^{\circ} \mathrm{C}$ for $48 \mathrm{~h}$. Strains that utilized the substrate as energy source grew as well-developed colonies; those that did not, either did not grow or grew as very tiny colonies. When an impression was required of the numbers of fermenting and non-fermenting organisms in a culture it was streaked on to plates of MacConkey agar base (Difco) containing $0.5 \%$ of the substrate; after incubation at $37^{\circ} \mathrm{C}$ for $24 \mathrm{~h}$ the proportion of fermenting to non-fermenting colonies was estimated.

The identification of strains whose substrate-utilizing ability was transmissible. Nutrient broth (Oxoid No. 2) was inoculated with $0.02 \mathrm{ml}$ volumes of broth cultures of an enterobacterial strain that utilized lactose, sucrose, raffinose, or salicin (prospective donor strain) and one of the $n a l^{r}$ prospective recipient strains. The recipient strains employed for lactoseutilization transmission were E. coli KI 2 Auxo and Salm. typhimurium 576; for sucrose-, raffinose- and salicin-utilization transmission was $E$. coli $\mathrm{KI} 2$ Proto; and for dulcitolutilization transmission were $E$. coli $\mathrm{KI} 2$ Auxo and E. coli PI04. Escherichia coli D282 was used as an additional recipient in raffinose-utilization transmission experiments in which the donor possessed the K88 antigen. The mixed cultures were incubated, without shaking, at $37^{\circ} \mathrm{C}$ for $24 \mathrm{~h}$ and then left at room temperature for another $24 \mathrm{~h}$ because it had been noted that some donors transmitted their plasmids at much higher frequencies at temperatures below $37^{\circ} \mathrm{C}$. They were then inoculated on to plates of the synthetic medium and of MacConkey agar base, both media containing the substrate under study and sodium nalidixate. The plates were incubated at $37{ }^{\circ} \mathrm{C}$, the former for $48 \mathrm{~h}$ and the latter for $24 \mathrm{~h}$. Any colonies that grew on the synthetic and any red-coloured ones that grew on the MacConkey plates were purified by plating and then inoculated on to the synthetic medium to confirm that they could utilize the particular substrate under test and that they were derived from the recipient strain. The fact that the $\mathrm{K} I 2$ recipient strains were $s p c^{\mathrm{r}}$ or $a m p^{\mathrm{r}}$ in addition to $\mathrm{nal}^{\mathrm{r}}$ and the availability of antisera against the other recipient strains facilitated their identification.

The rate of Sac transmission at different temperatures. Broth cultures of a strain whose sucrose-utilizing ability $\left(\mathrm{Sac}^{+}\right)$was transmissible and a $\mathrm{nal}^{\mathrm{r}}$ prospective recipient strain were both grown at one or other of the temperatures to be studied and then inoculated in $\mathbf{~ m l}$ amounts into the same $10 \mathrm{ml}$ of broth pre-incubated at that temperature. The mixed culture was incubated at that temperature for $24 \mathrm{~h}$. Then the number of prospective recipient organisms present was counted on ordinary MacConkey agar containing sodium nalidixate, and the number that had become $\mathrm{Sac}^{+}$was counted on the synthetic medium containing sucrose and sodium nalidixate; if the donor strain possessed an antibiotic resistance determinant, counts were also made on ordinary MacConkey agar containing sodium nalidixate and the antibiotic to which the determinant conferred resistance.

The effect of passaging $\mathrm{Sac}^{+}$strains in broth at different temperatures. Sac ${ }^{+}$strains were 
passaged daily in $10 \mathrm{ml}$ broth maintained at 37 or $44{ }^{\circ} \mathrm{C}$, the inoculum for each passage consisting of approximately $\mathrm{IO}^{4}$ viable organisms. After each passage, the cultures were streaked on MacConkey agar base containing sucrose and the proportions of $\mathrm{Sac}^{+}$and $\mathrm{Sac}^{-}$ colonies estimated.

The identification of strains possessing transfer factors only or genetic determinants only. This was achieved by mobilization tests (Anderson, 1965) employing the methods described by Smith \& Gyles (I970) and Smith \& Linggood (I970). The presence of a transfer factor in a strain was identified by its ability to mobilize a streptomycin/sulphonamide or a tetracycline (Tet) resistance determinant or a Sac determinant in a Tra ${ }^{-}$strain of E. coli KI2. Strains of $E$. coli $\mathrm{K}$ I 2 possessing $\mathrm{F}$, I or other transfer factors were used to identify $\mathrm{Tra}^{-}$strains possessing mobilizable determinants [I = Idrd(I); Meynell, I968]. In attempts to mobilize determinants for substrate-utilizing ability, transfer factors linked to a Tet determinant were first introduced into the strains possessing these determinants and the resulting $\mathrm{Tet}^{+}$forms of these strains then mated with an appropriate prospective recipient strain. The first part of this procedure was also employed when it was desired to introduce additional transfer factors into strains that already possessed one.

Elimination of plasmids from strains. This was attempted using acridine orange by the method of Hirota (1960), ethidium bromide by the method of Bouanchaud, Scavizzi \& Chabbert (1968) and sodium lauryl sulphate by the method of Tomoeda, Inuzuka, Kubo \& Nakamura (1968).

Fertility-inhibiting $(f)$ character of transfer factors. An F-linked Tet determinant was transmitted to an $E$. coli $\mathrm{KI} 2$ strain possessing the transfer factor under examination. This $\mathrm{Tet}^{+}$strain was then tested for visible lysis by the MS2 phage (Davis, Strauss \& Sinsheimer, I96I). The result was confirmed by phage-testing an $E$. coli $\mathrm{KI} 2 \mathrm{Hfr}$ strain to which the transfer factor with a determinant had been transmitted.

Hydrogen sulphide production. The method described by Cruikshank ( I970) was employed.

Detection of strains possessing the K88 antigen. This was achieved by slide agglutination tests with appropriate antisera.

Haemolysin production. This was detected by spot-inoculating broth cultures on to plates of 'washed sheep blood' agar (Smith \& Halls, 1967).

Detection of production of heat-labile enterotoxin. This was achieved by the rabbit ligated intestine test employing the method of Smith \& Linggood (197I).

The survival of $\mathrm{Sac}^{+}$and $\mathrm{Sac}^{--}$organisms of Salm. typhimurium in the alimentary tract of chicks. Approximately $3 \times 10^{8}$ viable organisms of a nalr strain of Salm. typhimurium of phage type 29 and a similar number of organisms of this strain in which a Sac determinant and its transfer factor had been established were mixed and given immediately by mouth to three-day-old chicks. At intervals, cloacal swabs were rubbed gently over the surface of plates of brilliant green agar (Oxoid, CM263) containing $0.5 \%$ sucrose, $20 \mu \mathrm{g}$ sodium nalidixate and I $\mu$ g novobiocin $/ \mathrm{ml}$; few of the organisms normally found in faeces grow on this medium and the colonies of those that do can easily be differentiated by their morphology from those of the Salm. typhimurium strain. The plates were incubated at $37^{\circ} \mathrm{C}$ for $24 \mathrm{~h}$ and the ratio of $\mathrm{Sac}^{+}$(colourless) colonies and $\mathrm{Sac}^{-}$(red) colonies of the Salm. typhimurium strain that grew on them estimated. Apart from one group whose diet was supplemented with $\mathrm{I} \%$ sucrose, all the chicks were fed on a commercial diet free from antibiotics.

The survival of Raf ${ }^{+}$and Raf organisms of E. coli in the alimentary tract of chickens. The technique was similar to that employed in the previous study except that the chicks were given equal numbers of organisms of a nal ${ }^{\mathrm{r}} s p c^{\mathrm{r}}$ mutant of a $\mathrm{Raf}^{-} \mathrm{O} 9: \mathrm{K} 9$ strain of $E$. coli and of organisms of this strain into which a Raf determinant and its transfer factor had been 
Table 1. The ability of 320 strains of E. coli to utilize different substrates and to transmit this property

$\begin{array}{lcc}\text { Substrate } & \begin{array}{c}\text { No. of strains that } \\ \text { utilized the substrate }\end{array} & \begin{array}{c}\text { No. of strains that } \\ \text { transmitted } \\ \text { this property }\end{array} \\ \text { Sucrose } & 152 & 3 \\ \text { Raffinose } & 163 & 27 \\ \text { Lactose } & 320 & 0 \\ \text { Dulcitol } & 99 & 0 \\ \text { Salicin } & 12 & 0\end{array}$

established. Chick faeces were cultivated on MacConkey agar base containing $0.5 \%$ raffinose and $20 \mu \mathrm{g}$ each of sodium nalidixate and spectinomycin and I $\mu \mathrm{g}$ of novobiocin $/ \mathrm{ml}$.

Bacterial counts. These were performed by the method of Miles \& Misra (1938).

\section{RESULTS}

The incidence in enterobacteria of ability to utilize different substrates and to transmit this property

The results of examining 320 apparently epidemiologically unrelated strains of $E$. coli for ability to ferment different substrates and to transmit this property are summarized in Table I. Of these strains, 85 had been isolated from humans, 34 from calves, five from lambs, 127 from pigs, 67 from chickens and two from dogs. About half of them had been isolated from the faeces of healthy subjects; the remainder had been associated with diarrhoea or bacteraemia. None of the strains was found to transmit their ability to utilize lactose, dulcitol or salicin but three ( $2 \%)$ of the 152 strains that utilized sucrose and $27(17 \%)$ of the I63 that utilized raffinose did. The transfer factor responsible for transmission of sucrose utilization in one of the three strains, HI 55, and transfer factors F and I were used in attempts to mobilize the genetic determinants for sucrose utilization in 50 of the $E$. coli strains; the attempts were unsuccessful.

Apart from the four strains of Salm. thompson received from Professor Kasitiya, which our examinations suggested were derived from the same clone and therefore will be referred to subsequently as the $\mathrm{Sac}^{+}$Salm. thompson strain, none of Ioo Salmonella strains (representing a variety of serotypes), I5 Shigella flexneri strains and six Sh. sonnei strains utilized sucrose. Nor did any of these strains utilize lactose, raffinose or salicin; 88 of the Salmonella strains utilized dulcitol but none of them transmitted this character.

The nature of the transmissible sucrose-utilizing ability in the E. coli and Salm. thompson strains

Of the three $E$. coli strains whose sucrose-utilizing ability was transmissible, two, HI 55 and HI 56, had been isolated from the faeces of humans and one, F62, had been isolated from the heart of a chicken suffering from bacteraemia.

In preliminary mating studies, $E$. coli $\mathrm{HI} 55$ transmitted its sucrose-utilizing determinant (Sac) to E. coli KI 2 more efficiently at $28^{\circ} \mathrm{C}$ than at $37^{\circ} \mathrm{C}$. Seven of 80 isolates of E. coli $\mathrm{KI} 2$ that had not acquired the Sac determinant of HI55 in these matings were found to have acquired its transfer factors (Tra). Of the seven isolates, two had acquired an $\mathrm{fi}^{+}$transfer factor subsequently designated TS (thermo-sensitive), and three an $\mathrm{fi}^{-}$transfer factor subsequently designated TR (thermo-resistant); the remaining two had acquired both 
Table 2. The transfer frequency of the sucrose-utilizing determinant (Sac) of E. coli $\mathrm{HI} 55$ and a tetracycline-resistance determinant $(\mathrm{Tet})$ from one strain of E. coli $\mathrm{KI} 2$ to another by the transfer factors of $\mathrm{HI} 55$ and by transfer factor $F$

Transfer factors
possessed by
donor strain of
E. coli $\mathrm{KI} 2$
TS
TR
TS and TR
F

\begin{tabular}{|c|c|c|c|c|c|c|c|c|c|}
\hline \multicolumn{2}{|c|}{$22{ }^{\circ} \mathrm{C}$} & \multicolumn{2}{|c|}{$28{ }^{\circ} \mathrm{C}$} & \multicolumn{2}{|c|}{$33{ }^{\circ} \mathrm{C}$} & \multicolumn{2}{|c|}{$37^{\circ} \mathrm{C}$} & \multicolumn{2}{|c|}{$4 \mathrm{I}^{\circ} \mathrm{C}$} \\
\hline $\mathrm{ac}$ & Tet & $\mathrm{Sac}$ & Tet & $\mathrm{Sac}$ & Tet & $\mathrm{Sac}$ & Tet & Sac & Tet \\
\hline$\frac{1}{-5}$ & $10^{0}$ & $10^{0}$ & $10^{0}$ & $10^{-2}$ & $10^{-2}$ & $10^{-4}$ & $10^{-4}$ & $10^{-5}$ & $\mathrm{IO}^{-5}$ \\
\hline-5 & $10^{-3}$ & $\begin{array}{l}10^{-4} \\
10^{0}\end{array}$ & $\mathrm{IO}^{-2}$ & $10^{-4}$ & $10^{-1}$ & $10^{-4}$ & $10^{-1}$ & $10^{-4}$ & $\begin{array}{l}10^{-2} \\
10^{-1}\end{array}$ \\
\hline $10^{-5}$ & $\mathrm{IO}^{-3}$ & $10^{-4}$ & $10^{-1}$ & $10^{-4}$ & $\begin{array}{l}10^{-1} \\
10^{0}\end{array}$ & $10^{-3}$ & $\begin{array}{l}10^{-1} \\
10^{0}\end{array}$ & $\begin{array}{l}10^{-4} \\
10^{-4}\end{array}$ & $\begin{array}{l}10^{-1} \\
10^{\prime \prime}\end{array}$ \\
\hline
\end{tabular}

* To the nearest power of 10.

transfer factors. TS and TR and transfer factor $F$ were then used to mobilize a tetracyclineresistance determinant (Tet) in an E. coli $\mathrm{KI} 2 \mathrm{Tet}^{+} \mathrm{Tra}^{-}$strain and to transfer it to an E. coli $\mathrm{KI} 2 \mathrm{Sac}^{+} \mathrm{Tra}^{-}$strain. The latter had been obtained by passaging at $44{ }^{\circ} \mathrm{C}$ an $E$. coli $\mathrm{KI} 2$ strain that had acquired the Sac determinant and TS transfer factor of HI 55 during mating with that strain (see below). As a result of these mobilization experiments, four different $\mathrm{Sac}^{+} \mathrm{Tet}^{+}$strains of $E$. coli $\mathrm{KI} 2$ were obtained, one possessing transfer factor $\mathrm{F}$, one transfer factor TS, one transfer factor TR and one both TS and TR. The effect of incubation temperature on the transmission of Sac and Tet from these four strains to an E. coli KI 2 strain is shown in Table 2. Transfer factor TS transmitted both determinants much more efficiently at the lower incubation temperatures and TR and $F$ transmitted them more efficiently at the higher temperatures. Tet, and to a lesser extent Sac, was transmitted by the strain possessing TS and TR at a high rate at all the incubation temperatures studied.

$\mathrm{The} \mathrm{Sac}^{+}$Salm. thompson strain possessed only one transfer factor, an $\mathrm{fi}^{-}$one. This transfer factor was closely associated with the Sac determinant and with a Tet determinant which the strain also possessed; the association between the Sac and Tet determinants was less close. For example, all isolates of $E$. coli KI2 selected from matings with the Salm. thompson strain as $\mathrm{Sac}^{+}$or $\mathrm{Tet}^{+}$were all $\mathrm{Tra}^{+}$and all isolates selected as $\mathrm{Sac}^{-} \mathrm{Tet}^{-}$were all Tra- , but about $10 \%$ of $\mathrm{Sac}^{+}$isolates were $\mathrm{Tet}^{-}$and $0 . \mathrm{I} \%$ of $\mathrm{Tet}^{+}$isolates were $\mathrm{Sac}^{-}$. The transfer factor of the Salm. thompson strain was more thermo-sensitive than the TS transfer factor of $E$. coli $\mathrm{HI} 55$ in that it transferred the Sac and Tet determinants very poorly both at 28 and $37^{\circ} \mathrm{C}$. For example, in matings with the Salm. thompson strain, the approximate proportions of E. coli $\mathrm{KI} 2$ organisms that acquired these determinants at 37 and at $28^{\circ} \mathrm{C}$ were $\mathrm{I}$ in $10^{6}$ and $\mathrm{I}$ in $10^{5}$, respectively, whereas the proportion that acquired them at $22{ }^{\circ} \mathrm{C}$ was I in $10^{2}$.

Both E. coli $\mathrm{Hr} 55$ and the $\mathrm{Sac}^{+}$Salm. thompson strain were lysogenic but not for E. coli KI 2 strains. Furthermore, their saccharose-utilizing ability could not be transmitted by membrane filtrates (average pore diameter $450 \mathrm{~m} \mu$ ) of broth cultures. It was transmitted during mixed culture at 22 or $28{ }^{\circ} \mathrm{C}$ to three strains of Salm. typhimurium belonging to different phage types, to one strain each of Salm. typhi, Salm. cholerae-suis, Salm. dublin, Salm. gallinarum and Sh. flexneri, to one of two strains of Sh. sonnei, to three strains of $E$. coli isolated from the faeces of healthy human beings, and to two strains of $E$. coli enteropathogenic for animals. Transmission was not achieved to one strain each of Proteus mirabilis, $P$. rettgeri and Pseudomonas aeruginosa.

The Sac plasmid was not eliminated from E. coli $\mathrm{HI} 55$ or from the Salm. thompson strain 
Table 3. The effect of passaging Sac ${ }^{+}$strains on their sucrose-utilizing ability

The $\mathrm{Sac}^{+}$strains were passaged daily in broth at $44^{\circ} \mathrm{C}$.

Strain

E. coli HI 55

Salm. typhimurium possessing the Sac determinant of $E$. coli $\mathrm{HI} 55^{*}$

$E$. coli $\mathrm{K} \mathbf{2}$ possessing the Sac determinant and the TS Tra of E. coli $\mathrm{HI} 55$

Salm. thompson

E. coli $\mathrm{KI} 2$ possessing the Sac and Tet determinants and Tra of Salm. thompson
No. of $\mathrm{Sac}^{-}$colonies amongst 200 colonies on day:

$\begin{array}{rrrrrrr}\text { I } & 2 & 3 & 4 & 5 & 6 & 7 \\ 0 & 0 & 0 & 0 & 0 & 0 & 0 \\ 0 & 0 & 0 & 0 & 0 & 0 & 0 \\ 0 & 0 & 0 & 0 & 0 & 0 & 0 \\ 0 & 6 & 70 & 150 & 170 & 170 & 180 \\ 0 & 0 & 5 & 30 & 100 & 140 & 160\end{array}$

* Not known whether the TR transfer factor (Tra) of HI 55 was present in addition to the TS one.

by treatment with acridine orange, ethidium bromide or sodium lauryl sulphate. However, after four passages in broth containing sodium lauryl sulphate, only $\mathrm{Sac}^{-}$organisms were found in cultures of one of three strains of E. coli KI 2 in which the Sac plasmid of HI 55 had been established; all the organisms isolated from cultures of the other two KI 2 strains similarly treated were still $\mathrm{Sac}^{+}$.

No $\mathrm{Sac}^{-}$organisms were found after seven daily passages in broth at $37^{\circ} \mathrm{C}$ of E. coli $\mathrm{HI} 55$, the $\mathrm{Sac}^{+}$Salm. thompson strain and three strains in which their Sac determinants had been established. However, after passage at $44{ }^{\circ} \mathrm{C}$ they were found in cultures of the Salm. thompson strain and an $E$. coli KI2 strain possessing its Sac determinant, their numbers increasing with each passage until eventually they were more common than $\mathrm{Sac}^{+}$ones (Table 3); all the $\mathrm{Sac}^{-}$isolates tested were also $\mathrm{Tet}^{-}$. No $\mathrm{Sac}^{-}$organisms were found after seven passages at $44{ }^{\circ} \mathrm{C}$ in cultures of HI55 or in cultures of one strain each of Salm. typhimurium and $E$. coli $\mathrm{KI} 2$ in which the Sac determinant of $\mathrm{Hr} 55$ had been established. Al] of 20 isolates from the seventh passage of the HI 55 culture had lost their TS transfer factor and so had 9 of 20 isolates from the passaged $\mathrm{Sac}^{+} \mathrm{KI} 2$ culture; isolates from the passaged $\mathrm{Sac}^{+}$Salm. typhimurium culture were not examined for transfer factor activity.

Unlike E. coli HI55 and the Salm. thompson strain, the other two strains that transmitted their ability to utilize sucrose, E. coli $\mathrm{F} 62$ and $\mathrm{HI} 56$, did so at very low rates. The proportion of $E$. coli KI 2 organisms that acquired the Sac determinants of these two strains during mixed culture was never higher than $\mathrm{I}$ in $10^{7}$; sometimes no $\mathrm{Sac}^{+} E$. coli $\mathrm{KI} 2$ organisms were isolated. Transfer was never observed at 22 or $28^{\circ} \mathrm{C}$, only at $37^{\circ} \mathrm{C}$. Both strains possessed antibiotic-resistance determinants, those of HI56 being transferred at a very high rate to $E$. coli $\mathrm{KI} 2$ and those of $\mathrm{F} 62$ at a moderate rate; their transfer factors were $\mathrm{fi}^{+}$. The establishment of transfer factors F or I in an E. coli KI2 strain in which the Sac determinant of F62 had previously been established increased the transfer rate of that determinant to the extent that approximately $\mathrm{I}$ in $\mathrm{IO}^{4}$ organisms of an $E$. coli $\mathrm{KI} 2$ recipient strain acquired it during mixed culture with these $\mathrm{F}^{+}$or $\mathrm{I}^{+}$donor strains. The corresponding figure for a similar experiment involving $\mathrm{F}$ and the Sac determinant of $E$. coli $\mathrm{HI} 56$ was $\mathrm{I}$ in $10^{6}$. Apart from transferring (on one occasion only) the Sac determinant of $E$. coli $\mathrm{F}_{2} 2$ to an $E$. coli strain isolated from a human and the Sac determinant of E. coli HI56 to a Salm. typhimurium strain, all attempts to transfer these determinants to the same range of recipient strains that 
Table 4. The classification of 320 strains of E. coli according to source, ability to utilize raffinose and ability to transmit this property

All the strains associated with diarrhoea were enteropathogenic.

\begin{tabular}{|c|c|c|c|c|}
\hline \multicolumn{2}{|c|}{ Source of strains } & \multirow[b]{2}{*}{ No. examined } & \multirow{2}{*}{$\begin{array}{l}\text { No. that } \\
\text { utilized } \\
\text { raffinose }\end{array}$} & \multirow{2}{*}{$\begin{array}{c}\text { No. that } \\
\text { transmitted } \\
\text { this property }\end{array}$} \\
\hline Host & Clinical condition & & & \\
\hline Humans & $\left\{\begin{array}{l}\text { Neonatal diarrhoea } \\
\text { Bacteraemia } \\
\text { Normal* }\end{array}\right.$ & $\begin{array}{l}25 \\
19 \\
41\end{array}$ & $\begin{array}{r}13 \\
5 \\
12\end{array}$ & $\begin{array}{l}0 \\
0 \\
0\end{array}$ \\
\hline Calves & $\left\{\begin{array}{l}\text { Neonatal diarrhoea } \\
\text { Bacteraemia } \\
\text { Normal* }\end{array}\right.$ & $\begin{array}{r}5 \\
2 \\
27\end{array}$ & $\begin{array}{r}0 \\
I \\
2 I\end{array}$ & $\begin{array}{l}0 \\
0 \\
0\end{array}$ \\
\hline Pigs & $\left\{\begin{array}{l}\text { Neonatal and post- } \\
\text { weaning diarrhoea } \\
\text { Normal* }\end{array}\right.$ & $\begin{array}{l}51 \\
72\end{array}$ & $\begin{array}{l}31 \\
22\end{array}$ & $\begin{array}{r}2 \mathrm{I} \\
0\end{array}$ \\
\hline Chickens & $\left\{\begin{array}{l}\text { Bacteraemia } \\
\text { INormal* }\end{array}\right.$ & $\begin{array}{l}50 \\
17\end{array}$ & $\begin{array}{r}44 \\
8\end{array}$ & $\begin{array}{l}5 \\
\text { I }\end{array}$ \\
\hline Others & Various & 7 & 6 & 0 \\
\hline
\end{tabular}

had been used in corresponding studies with E. coli HI55 and the Sac ${ }^{+}$Salm. thompson strain were unsuccessful.

Escherichia coli $\mathrm{KI} 2$ strains in which the Sac determinants of E. coli HI55, HI56, F62 and the $\mathrm{Sac}^{+} \mathrm{Salm}$. thompson strain had been established, were grown in peptone water containing 24 different 'sugars' used to identify bacteria. Apart from fermenting sucrose, they had neither acquired nor lost the ability to ferment any of the other substrates except that they now fermented raffinose. Because only about $\mathrm{I}$ in $10^{6}$ organisms of cultures of these strains grew into colonies on the synthetic medium containing raffinose as sole energy source, this event was considered mutational in origin.

The nature of the transmissible raffinose-utilizing ability in the E. coli strains

The 320 strains of $E$. coli referred to in Table I were classified according to their source, their ability to utilize raffinose and their ability to transmit this property (Table 4). A higher proportion of the strains from pigs affected with $E$. coli diarrhoea than of the strains from other sources transmitted the ability to utilize raffinose. Because of this, an additional 47 apparently epidemiologically-unrelated $E$. coli strains enteropathogenic for pigs were examined and the results for all 98 classified serologically (Table 5) with particular regard to possession of the K88 antigen, known to be controlled by a transmissible plasmid in some porcine enteropathogenic strains (Ørskov \& Ørskov, 1966). Cultures of E. coli K I 2 or D282 that acquired raffinose-utilizing ability $\left(\mathrm{Raf}^{+}\right)$from these enteropathogenic strains were examined, one per donor, for K88 antigen and for two other characters also known to be transmissible in some porcine enteropathogenic strains, haemolysin production (Smith \& Halls, 1967) and enterotoxin production (Smith \& Halls, 1968). Irrespective of their other antigens, all $4 \mathrm{I}$ enteropathogenic strains possessing the K88 antigen utilized raffinose and 37 of them transmitted this property to the $E$. coli $\mathrm{KI} 2$ or D282 recipient strains. Furthermore, all $37 \mathrm{Raf}^{+}$cultures of $E$. coli $\mathrm{K} 12$ or $\mathrm{D} 282$ obtained from these matings also acquired the determinants for K88 production from the donor strains. Fourteen of them also acquired the determinants for enterotoxin production (Ent) but only one had also acquired the 
Table 5. The ability of different serotypes of E. coli enteropathogenic for pigs to utilize raffinose, to transmit this property and to co-transmit other properties

The $\mathrm{K}$ antigens in quotation marks are not Internationally-recognized ones. All the $\mathrm{K}^{8} 8^{+}$strains were enterotoxigenic and haemolytic; of the $\mathrm{K} 88^{-}$strains, all except $\mathrm{II}$ were enterotoxigenic and all except five were haemolytic.

$\begin{aligned} & \text { No. of } \\ & \text { strains }\end{aligned}$ No. that No. that No. that co-transmitted* production of
examilized transmitted

Possessing $\mathrm{K} 88$ antigen

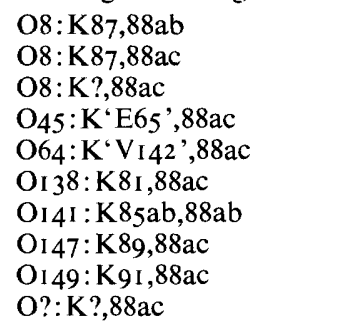

Not possessing K88 antigen

O9:K9
O45:K'E65,
O64:K?
OroI $: \mathrm{K} ?$
Or $38: \mathrm{K} 8 \mathrm{r}$
Or $39: \mathrm{K} 82$
Or $4 \mathrm{I}: \mathrm{K} 85 \mathrm{ab} \rightarrow$ ac
Or41 $: \mathrm{K} 85 \mathrm{ac}$

* This means that the particular isolate of the E. coli $\mathrm{KI} 2$ or $\mathrm{D} 282$ recipient strain selected as $\mathrm{Raf}^{+} \mathrm{had}^{-}$ also acquired the $\mathrm{K} 88$, enterotoxin or haemolysin determinant from the donor; testing ten $\mathrm{Raf}^{+}$isolates from the same mating, instead of one, increased the detection rate of donors of enterotoxin or haemolysin production; the final number detected is given in parentheses.

determinants for haemolysin production (Hly). When ten $\mathrm{Raf}^{+}$recipient cultures from each of the 37 matings with the Raf donor strains were examined, instead of one, the number of matings in which Ent transmission was detected increased from I4 to 30 and the number in which Hly transmission was detected increased from I to 2 ; for convenience, the ten colonies in each batch were incubated together in broth before testing for enterotoxin production. Of the 37 Raf donor strains, I4 were resistant to tetracyclines, I4 to streptomycin, 8 to chloramphenicol and 5 to neomycin. Antibiotic sensitivity tests on the $37 \mathrm{Raf}^{+}$E. coli KI 2 or D282 recipient cultures revealed that 6 of the donor strains had co-transmitted their tetracycline resistance with raffinose-utilizing ability, 3 their streptomycin resistance, 8 their chloramphenicol resistance and 4 their neomycin resistance.

In contrast to the $\mathrm{K}^{8} 8^{+}$strains, only $\mathrm{I} 4$ of the 57 enteropathogenic strains that did not produce the K88 antigen utilized raffinose and none of them transmitted this property. Attempts to mobilize the genes for raffinose utilization in these I 4 strains by transfer factors $\mathrm{F}$ and I were unsuccessful. Nine of the $\mathrm{Raf}^{-} \mathrm{K}^{-} 8^{-}$enteropathogenic strains were mated with a $\mathrm{Raf}^{+} \mathrm{K} 88^{+}$enteropathogenic strain, $\mathrm{P} 233$, of antigenic structure $\mathrm{O} 8: \mathrm{K} 87,88 \mathrm{ac}$. All nine acquired the Raf determinant of $\mathrm{P}_{233}$, the $\mathrm{Raf}^{+}$isolates tested being $\mathrm{K}^{8} 8^{+}$also.

To study the relationship between the K88 and Raf determinants more closely, four high-transmitting $\mathrm{K}_{88^{+}}$enteropathogenic strains were mated with one or other of five prospective recipient strains. No recipient organisms that were $\mathrm{Raf}^{+} \mathrm{K} 88^{-}$or $\mathrm{Raf}^{-} \mathrm{K} 88^{+}$ 
were isolated from any of these matings - all of II $5 \mathrm{Raf}^{+}$isolates were $\mathrm{K}^{8} 8^{+}$and all of $\mathrm{I} 60$ $\mathrm{Raf}^{-}$isolates were $\mathrm{K}^{-} 8^{-}$. This close relationship, however, was not always noted. For example, three OI4I : K85ab,88ab strains that were not tested for raffinose utilization until they had been maintained on Dorset egg medium at $5{ }^{\circ} \mathrm{C}$ for about two years yielded $\mathrm{Raf}^{+}$and $\mathrm{Raf}^{-}$ colonies, all of which were $\mathrm{K} 88^{+}$. Nor was a close relationship noted when cultures of eight of the $\mathrm{K} 88^{+}$enteropathogenic strains were treated with sodium lauryl sulphate or acridine orange. $\mathrm{K} 88^{-}$- organisms were isolated from all eight as a result, those from seven of them being $\mathrm{K}^{8} 8^{-} \mathrm{Raf}^{+}$; no $\mathrm{Raf}^{-}$organisms at all were isolated from these seven treated strains. Four of seven $\mathrm{K}^{8} 8^{-} \mathrm{Raf}^{+}$cultures were still able to transmit their Raf determinants, but three were no longer able to; of two such cultures selected from one treated strain, one could still transmit its Raf determinant and the other could not.

All 43 strains referred to in Tables 4 and 5 that transmitted raffinose-utilizing ability did so much more efficiently at $37^{\circ} \mathrm{C}$ than at 28 or $22{ }^{\circ} \mathrm{C}$. Strains that acquired the Raf determinant did not, as a result, acquire the ability to utilize sucrose or any of the other substrates tested. Some strains were much better donors than others. For example, in matings between 27 donor strains and $E$. coli KI 2, the proportion of KI 2 organisms that acquired the Raf determinant varied from $\mathrm{I}$ in 2 to $\mathrm{I}$ in $10^{7}$ (median, $\mathrm{I}$ in 500). None of the 43 Raf donor strains produced hydrogen sulphide so it was impossible to obtain additional information on the significance of the high incidence of transmissible raffinose-utilizing ability amongst E. coli strains that transmit the ability to produce hydrogen sulphide (Ørskov \& Ørskov, I973). The results of $\mathrm{fi}$ tests indicated that $\mathrm{I} 2$ of $\mathrm{I} 6$ enteropathogenic $\mathrm{Raf}^{+}$strains and four of six non-enteropathogenic ones possessed $\mathrm{f}^{-}$transfer factors, the other six possessing $\mathrm{fi}^{+}$ones.

Raffinose-utilizing ability was transmitted from an enteropathogenic and a non-enteropathogenic $\mathrm{Raf}^{+}$strain of $E$. coli to the same E. coli, Salmonella and Shigella strains into which sucrose-utilizing ability had been transmitted from E. coli HI 55 and from the Sac ${ }^{+}$ Salm. thompson strain; the strains that had acquired the Raf determinant from the enteropathogenic strain also acquired its K88 determinant. As in the case of the $\mathrm{Sac}^{+}$strains, the $\mathrm{Raf}^{+}$strains failed to transmit to one strain each of Pr. mirabilis, Pr. rettgeri and Pseudomonas aeruginosa.

\section{The survival of $\mathrm{Sac}^{+}$and Sac organisms of Salm. typhimurium in the alimentary tract of chicks}

The proportion of $\mathrm{Sac}^{+}$and $\mathrm{Sac}^{-}$Salm. typhimurium organisms in the faeces of nine chicks that had been given equal numbers of each orally was assessed on eleven occasions during the next 18 days. The $\mathrm{Sac}^{+}$strain had been obtained by establishing the Sac determinant and TS transfer factor of E. coli $\mathrm{HI} 55$ in the $\mathrm{Sac}^{-}$strain. Of the 99 faecal specimens examined, 55 yielded colonies of the Salm. typhimurium strain. The proportion of the colonies obtained from each of these 55 specimens that were $\mathrm{Sac}^{+}$varied from o to $75 \%$ (median $10 \%$ ); in only three specimens did the $\mathrm{Sac}^{+}$organisms outnumber the $\mathrm{Sac}^{-}$ones. Usually more $\mathrm{Sac}^{-}$than $\mathrm{Sac}^{+}$organisms were found in the contents of the crop, small intestine and caeca of the chicks when they were killed at the end of the experiment.

When the experiment was repeated, but employing food containing I $\%$ sucrose, the results were the same. In this experiment, ten uninoculated chicks were kept in contact with the ten infected ones. They subsequently became infected, the numbers of the $\mathrm{Sac}^{-} \mathrm{Salm}$. typhimurium organisms isolated from their faeces, crop, small intestine and caeca greatly outnumbering the $\mathrm{Sac}^{+}$ones.

To ensure that the results of these infection experiments were not a reflection of loss of the 
Sac determinant by $\mathrm{Sac}^{+}$organisms, they were repeated, the chicks being infected with $\mathrm{Sac}^{+}$ Salm. typhimurium organisms only. Sac ${ }^{-}$Salm. typhimurium organisms were never isolated from the faeces of these chicks.

\section{The survival of $\mathrm{Raf}^{+}$and Raf- organisms of an O9:K9 strain of E. coli in the alimentary tract of chicks}

The proportion of $\mathrm{Raf}^{+}$and $\mathrm{Raf}^{-}$organisms of an $\mathrm{O}_{9}: \mathrm{K}_{9}$ strain of $E$. coli in the faeces of ten chicks that had been given equal numbers of both organisms orally was assessed on seven occasions during the next $\mathrm{I} 6$ days. The $\mathrm{Raf}^{+}$strain had been obtained by establishing the Raf determinant and transfer factor of a non-enteropathogenic $E$. coli strain in the Rafstrain. During the first seven days after infection, $\mathrm{Raf}^{+} \mathrm{O}_{9}: \mathrm{K}_{9}$ organisms were found rather more commonly in the faeces of most of the chicks than were the Raf- ones. At the subsequent examinations, however, the reverse was true - at the two final examinations all ten specimens yielded more $\mathrm{Raf}^{-}$than $\mathrm{Raf}^{+} \mathrm{O}_{9}: \mathrm{K}_{9}$ organisms.

\section{DISCUSSION}

There seems little doubt that sucrose-utilizing ability in the Salm. thompson strain and in $E$. coli HI 55 is controlled by transmissible plasmids. The significantly increased transfer rate that resulted from the establishment therein of transfer factors $F$ or I suggested that this might also be the case in $E$. coli $\mathrm{F} 62$ and $\mathrm{HI} 56$, strains which previously had transferred their ability to utilize sucrose at very low frequencies. Both the Salm. thompson strain and E. coli HI55 possessed transfer factors belonging to the thermo-sensitive (TS) class, first described by Terawaki, Takayasu \& Akiba (1967) in a strain of Proteus vulgaris. The transfer factor of the Salm. thompson strain was identified as TS because not only was its Sac determinant transmitted much more efficiently at low temperatures but it was eliminated by incubation at $44{ }^{\circ} \mathrm{C}$. The identification of the TS transfer factor of $E$. coli HI 55 presented a more difficult problem in that, although its Sac determinant was transmitted much more efficiently at temperatures below $37^{\circ} \mathrm{C}$, it was not eliminated by incubation at $44{ }^{\circ} \mathrm{C}$. However, the Sac determinant in this strain was not linked to the transfer factor and therefore was not a reliable indicator of the presence of the transfer factor; this was demonstrated when all 20 isolates from a culture of $E$. coli $\mathrm{HI} 55$ that had been passaged at $44{ }^{\circ} \mathrm{C}$ were found to have lost their TS transfer factor but to be still $\mathrm{Sac}^{+}$. The elucidation of the transfer factor status of $E$. coli HI 55 was further complicated in that it possessed, in addition to the TS transfer factor, a transfer factor (TR) of the more usual type, i.e. one that transfers most efficiently at $37^{\circ} \mathrm{C}$. The TR transfer factor could transmit the Sac determinant, albeit poorly, and so could transfer factors $F$ and $I$, indicating the absence of an exclusive relationship between Sac determinants and TS transfer factors. The TS transfer factors of the $\mathrm{Sac}^{+} \mathrm{Salm}$. thompson strain and of $E$. coli HI55 were obviously different from each other, in that they reacted differently to the fi test and transferred Sac most efficiently at different temperatures, the Salm. thompson transfer factor at $22{ }^{\circ} \mathrm{C}$ and the $E$. coli HI 55 transfer factor at $28^{\circ} \mathrm{C}$. Le Minor et al. (I973) provided no information on the effect of temperature on the frequency with which three Salmonella strains they examined transmitted their Sac determinant, so it remains to be discovered whether TS transfer factors are commonly associated wth Sac determinants in nature. The fact that the Sac determinants of the Salm. thompson strain and of E. coli $\mathrm{HI} 55$ were transmitted at such low frequencies at $37^{\circ} \mathrm{C}$, and the fact that the Sac determinant of HI 55 did not confer survival value on Salm. typhimurium in the alimentary tract of chicks, make it unlikely that these Sac determinants could spread to other entero- 
bacteria in the alimentary tract of homothermic animals. Such spread would be more likely to occur in poikilothermic animals or in sewage. Both strains may well have acquired their determinants in either of these two environments.

The apparent lack of contribution of transmissible raffinose-utilizing ability to the survival of $E$. coli in the alimentary tract of chicks also raises the question of the high incidence of strains found to possess this character. However, it was principally a feature of the porcine enteropathogenic strains that possessed the K88 antigen and in these strains the Raf and K88 determinants, although not linked, were closely associated with each other. Although the association between these two determinants and the enterotoxin determinant (Ent) was not so obvious, there was a tendency for all three determinants to be transmitted together. It is difficult to understand how Ent can confer a survival value to organisms possessing it. This is not the case with $\mathrm{K} 88$ because it enables $E$. coli organisms possessing it to proliferate in the anterior small intestine of pigs (Smith \& Linggood, 197I; Jones \& Rutter, I972), a region which normally contains relatively few bacteria. It may be that Raf and Ent owe their present ecological status, at least in part, to their association with the K88 determinant rather than to any specific contribution to survival they themselves make. It is significant in this respect that naturally-occurring $\mathrm{K} 88^{-}$porcine enteropathogenic strains possess a transmissible Ent determinant different from that possessed by naturally-occurring $\mathrm{K} 88^{+}$strains (Smith \& Gyles, I970) and that none of the K88- enteropathogenic strains found to utilize raffinose in the present study could transmit that property although transmissible Raf determinants could be established in them.

The examination of recipient organisms that had received the Raf determinant for other transmissible characters possessed by the donor strains, e.g. K88, Ent and resistance determinants, provided an excellent example of how transmissible characters for which good selection methods exist, e.g. Raf, can be utilized to detect transmission of characters for which only poor selection methods exist, e.g. K88 and Ent. These studies also warn against ascribing properties to a particular transmissible determinant when they may, in reality, be those of a different but closely associated determinant.

We are grateful to Mr P. Green and Miss Margaret Lovell for their capable technical help. Our thanks are also due to Professor E. S. Anderson, Dr P. M. Biggs, Miss Doreen Cooper, Professor S. S. Kasitiya and Mrs Margaret Webster for help and assistance in a variety of ways.

\section{REFERENCES}

Anderson, E. S. (1965). A rapid screening test for transfer factors in drug-sensitive Enterobacteriaceae. Nature, London 208, I0I6-IOI7.

Bouanchaud, D. H., Scavizzi, M. R. \& Chabbert, Y. A. (i968). Elimination by ethidium bromide of antibiotic resistance in Enterobacteriaceae and staphylococci. Journal of General Microbiology 54, $417-425$.

Cruikshank, R. (1970). In Medical Microbiology, i ith edn., p. 826. Edited by R. Cruikshank. Edinburgh and London: F. \& S. Livingstone.

Davis, J. E., Strauss, J. H., Jun. \& Sinsheimer, R. L. (1961). Bacteriophage MS2: another RNA phage. Science, New York r34, 1427.

Hirota, Y. (1960). The effect of acridine dyes on mating type factors in Escherichia coli. Proceedings of the National Academy of Sciences of the United States of America 46, 57-64.

Jones, G. W. \& RUTTER, J. M. ( I972). Role of K88 antigen in the pathogenesis of neonatal diarrhoea caused by Escherichia coli in piglets. Infection and Immunity 6, 91 8-927.

Le Minor, L., Coynault, C., Rohde, R., Rowe, B. \& Aleksic, S. (1973). Localisation plasmidique du déterminant génétique du caractère atypique 'saccharose ${ }^{+}$' des Salmonella. Annales de Microbiologie (Institut Pasteur) 124 B, 295-306. 
Meynell, G. G. (1968). Bacterial sex factors. Annual Report of the Lister Institute for Preventive Medicine. Miles, A. A. \& Misra, S. S. (1938). The estimation of the bactericidal power of blood. Journal of Hygiene $\mathbf{3}^{8}$, $732-749$.

ØRSKOV, I. \& ØRSKOV, F. (1966). Episome-carried surface antigen K88 of Escherichia coli. I. Transmission of the determinant of the K88 antigen and influence on the transfer of chromosomal markers. Journal of Bacteriology 9r, 69-75.

ØRSKov, I. \& ØRSKov, F. (1973). Plasmid-determined $\mathrm{H}_{2} \mathrm{~S}$ character in Escherichia coli and its relation to plasmid-carried raffinose fermentation and tetracycline resistance characters. Journal of General Microbiology 77, 487-499.

Smith, H. Williams \& Gyles, C. L. (1970). The relationship between two apparently different enterotoxins produced by enterpathogenic strains of Escherichia coli of porcine origin. Journal of Medical Microbiology 3, 387-40I.

Smith, H. Williams \& Halls, S. (1967). The transmissible nature of the genetic factor in Escherichia coli that controls haemolysin production. Journal of General Microbiology 47, I53-16I.

Smith, H. Williams \& Halls, S. (1968). The transmissible nature of the genetic factor in Escherichia coli that controls enterotoxin production. Journal of General Microbiology 52, 319-334.

Smith, H. Williams \& Linggood, M. A. (1970). Transfer factors in Escherichia coli with particular regard to their incidence in enteropathogenic strains. Journal of General Microbiology 62, 287-299.

Smith, H. Williams \& LingGood, M. A. (197I). The transmissible nature of enterotoxin production in a human enteropathogenic strain of Escherichia coli. Journal of Medical Microbiology 4, $301-305$.

TerawaKi, Y., TAKaYASU, H. \& AKIBA, T. (1967). Thermosensitive replication of a kanamycin resistance factor. Journal of Bacteriology 94, 687-690.

Tomoeda, M., Inuzuka, M., Kubo, N. \& Nakamura, S. (I968). Effective elimination of drug resistance and sex factors in Escherichia coli by sodium dodecyl sulphate. Journal of Bacteriology 95, 1078. 